\title{
EVALUATION OF ANXIOLYTIC EFFECT OF MELILOTUS OFFICINALIS EXTRACTS IN MICE
}

\author{
SARABJIT KAUR ${ }^{1}$, ANUPAM SHARMA ${ }^{2}$, PREET MOHINDER SINGH BEDI ${ }^{1 *}$
}

${ }^{1}$ Department of Pharmaceutical Sciences, Guru Nanak Dev University, Amritsar - 143 005, Punjab, India. ${ }^{2}$ University Institute of Pharmaceutical Sciences, Panjab University, Chandigarh, India. Email: bedi_preet@yahoo.com

Received: 19 January 2017, Revised and Accepted: 04 May 2017

ABSTRACT

Objective: Anxiety is one of the most common and serious mental illness affecting humankind and its extensiveness is on the rise at an alarming rate. Anxiolytic substances are highly acclaimed in the ranking of the most utilized drugs by human. The clinical applications of most widely used anxiolytic agents, that is, benzodiazepines are restricted by their undesirable side effects. Therefore, the development of new pharmacological agents for the treatment of this problem is well justified. Among medicinal plants, Melilotus officinalis (yellow sweet clover) has been recommended for relief of insomnia, convulsions, and as nervine tonic in traditional system of medicine. Nevertheless, no pharmacological studies have thus far evaluated its anxiolytic effect. Therefore, the aim of this study was to evaluate antianxiety effect of different extracts of $M$. officinalis in mice.

Methods: The extracts of roots and aerial parts of the plant were prepared according to the polarity, that is, petroleum ether, chloroform, ethanol, and water. The anxiolytic effects of petroleum ether, chloroform, ethanol, and aqueous extract of aerial parts and roots of the plant (50, 100 , and $200 \mathrm{mg} / \mathrm{kg}$, p.o) were examined in albino mice using elevated plus maze (EPM) and mirror-chamber models of anxiety. High-performance thin layer chromatography (HPTLC) studies were carried out using toluene: Acetone: Formic acid as mobile phase.

Results: Various extracts prepared from roots did not produce significant effect in both the models, whereas the ethanol extract prepared from aerial parts at 100 and $200 \mathrm{mg} / \mathrm{kg}$ showed a significant anxiolytic effect as compared to control and standard group. The petroleum ether, chloroform, and water extracts $(50,100$, and $200 \mathrm{mg} / \mathrm{kg})$ of the aerial parts of the plant did not produce meaningful effects in this study. HPTLC analysis of the ethanol extract revealed the presence of nine components.

Conclusion: These results suggest that the ethanol extract of aerial parts of $M$. officinalis plant has statistically significant dose-dependent antianxiety activity which can be attributed to the presence of coumarin, and flavonoid compounds in it.

Keywords: Melilotus officinalis, Aerial parts, Anxiolytic, High-performance thin layer chromatography.

(c) 2017 The Authors. Published by Innovare Academic Sciences Pvt Ltd. This is an open access article under the CC BY license (http://creativecommons. org/licenses/by/4. 0/) DOI: http://dx.doi.org/10.22159/ajpcr.2017.v10i6.17183

\section{INTRODUCTION}

The plant Melilotus officinalis commonly known as yellow sweet clover or honey lotus belonging to family Leguminosae (Fabaceae) is a sweet smelling annual or biennial herb. This plant has wide spectrum of pharmacological activities and all of its parts are used for medicinal purposes [1]. The plant is used for the treatment of inflammation, edema, foot ulcers, and headache [2]. In addition, M. officinalis has been reported to be a hypotensive, antioxidant, antifungal [3-5], and analgesic agent [6].

Substantial phytochemical work has been done on this plant which shows the presence of coumarin, glycosides, saponins, triterpenoid sapogenols [7-10], and phenolic compounds, for example, quercetin, kampferol, rutin, and umbelliferone [11].

The plant yellow sweet clover has traditionally been used in the treatment of convulsions, insomnia, and as nervine tonic $[12,13]$. Ethnopharmacological reports on $M$. officinalis suggest that this plant was used for the treatment of neuropsychiatric disorders.

Despite a history of use of this plant as medicine for the treatment of neuropsychiatric disorders, this plant has not been investigated so far to substantiate these therapeutic claims and no experimental study is available on antianxiety evaluation of the plant. Therefore, it was envisioned to investigate the anxiolytic effect of different extracts of roots and aerial parts of $M$. officinalis in mice using elevated plus maze (EPM) and mirror chamber test as animal models.

\section{METHODS}

\section{Plant material}

The roots and aerial parts of yellow sweet clover M. officinalis were procured from Hind herbs store, Village Khurrampur, Saharanpur, Uttar Pradesh, and authenticated at the Department of Botanical and Environmental Sciences where the herbarium specimen was deposited (SR/Bot.Sci./1667) for the future reference.

\section{Preparation of the plant extracts}

The dried roots and aerial parts of $M$. officinalis $(2 \mathrm{~kg})$ were reduced to moderately coarse powder by passing through sieve no. 22. The powdered drug was Soxhlet extracted with petroleum ether, chloroform, and ethanol successively [14]. The ultimate dried marc of the plant was macerated with distilled water for $24 \mathrm{hrs}$ and filtered. Then, the extractives were obtained on evaporation of solvents using rotary vacuum evaporator and dried extracts were preserved at $4^{\circ} \mathrm{C}$ for the future use.

\section{Drugs}

Diazepam hydrochloride $(2 \mathrm{mg} / \mathrm{kg}$ ) was used as a standard drug in the present study. All chemicals and solvents were of analytical grade.

\section{Animals and treatment regimens}

Albino mice weighing 20-25 g of either sex were used. The animals were kept in rooms maintained at $25^{\circ} \mathrm{C}$ with a $12 \mathrm{hrs} \mathrm{light/dark} \mathrm{cycle} \mathrm{and}$ were given standard laboratory feed and water. They were familiarized with their surroundings for 2 weeks before starting the experiment. Groups of six mice (20-25 g) were used in all sets of experiments. The 
experiments were conducted in a semi-sound proof laboratory. All the experiments were conducted according to the guidelines of the Committee for the Purpose of Control and Supervision of Experiments on Animals, Ministry of Environment and Forests, India, and protocols were duly approved by the Institutional Animal Ethics Committee, Guru Nanak Dev University, Amritsar. The animals were divided into eight groups containing six mice each and given treatment - Group I - control ( $0.5 \%$ carboxymethylcellulose), Group II - treated animals received diazepam ( $2 \mathrm{mg} / \mathrm{kg}$ ), and Group III, IV, and V were treated with different root extracts of the plant at a dose of 50,100 , and $200 \mathrm{mg} / \mathrm{kg}$, respectively. Group VI, VII, and VIII were treated with different extracts of the plant prepared from aerial parts at a dose of 50,100, and $200 \mathrm{mg} / \mathrm{kg}$ orally. Initially, a preliminary screening was carried out to select the dose for anxiolytic activity and three doses, namely, 50,100, and $200 \mathrm{mg} / \mathrm{kg}$ of M. officinalis were selected.

\section{EPM model}

The maze comprised two open arms of $50 \times 10 \mathrm{~cm}$ and two closed arms of $50 \times 10 \times 40 \mathrm{~cm}$, extending from a central platform and elevated to a height of $50 \mathrm{~cm}$ above the floor. The maze was placed inside a light and sound-attenuated room. The experimental animals were treated with vehicle, diazepam $(2 \mathrm{mg} / \mathrm{kg})$ and the extracts were given orally at a dose of 50,100, and $200 \mathrm{mg} / \mathrm{kg}$ before evaluation in the maze. Dose administration schedule was adjusted in such a way that each mouse was placed on EPM after 60 minutes of drug treatment. Every measure was taken to ensure that mice are not exposed to any external stimuli, other than the height of the plus maze which could elicit anxiety in mice. Mice were individually placed on the center of the maze facing an open arm, and the number of entries and the time spent in closed and open arms were recorded during a 5 minutes observation period $[15,16]$.

\section{Mirror chamber test}

The mirrored-chamber apparatus comprised a mirrored cube $30 \mathrm{~cm}$ on a side) open on one side that was placed inside a square wooden box $(40 \times 40 \times 30.5 \mathrm{~cm})$. The mirrored cube was constructed of five pieces of mirrored glass. The mirrors used were mirrored on one surface only (back surface being painted dark brown). The three mirrored side panes, a top pane, and floor pane faced the interior of the cube. The mirrored cube was placed in the center of the wooden container to form a $5 \mathrm{~cm}$ corridor that completely surrounded the mirror chamber. A mirror was also placed on the container wall so that it faced the single open side of the mirrored chamber. The other three walls of the container were painted dark brown. 60 minutes after the administration of the control, test drug, and standard, the mice were placed individually in the chamber of mirrors at a fixed corner. During 5 minutes test period, the mean time spent and number of entries in the mirror chamber were observed [17].

\section{High-performance thin layer chromatography (HPTLC) studies}

Pre-coated and pre-activated TLC plates (E. Merck No. 5548) of silica gel $60 \mathrm{~F}_{254}$ with the support of aluminum sheets having thickness of $0.1 \mathrm{~mm}$ were used. $2 \mathrm{~g}$ of ethanol extract was weighed accurately and dissolved in $20 \mathrm{~mL}$ of ethanol. Solutions were then refluxed for 30 minutes on water bath at $60-70^{\circ} \mathrm{C}$. The extracts were cooled, filtered, and finally the volume was made up to $20 \mathrm{~mL}$ with ethanol. The sample was applied on TLC plate in the form of band using an automatic sample application device (LINOMAT, CAMAG) with bandwidth of $9 \mathrm{~mm}$. The quantity of sample applied was $10 \mu \mathrm{L}$. After optimization of mobile phase, a solvent system comprised Toluene:Acetone:Formic acid (7:3:0.5) was selected to give the best resolution. The detecting reagent was anisaldehyde in sulfuric acid followed by heating at $110^{\circ} \mathrm{C}$ for 5 minutes.

\section{Preliminary phytochemical screening of ethanol extract}

The ethanol extract was screened for different classes of phytoconstituents, that is, alkaloids, glycosides, coumarins, and flavonoids [18].

\section{Statistical analysis}

The anxiolytic activities of the extracts, diazepam, and control were analyzed by one-way ANOVA. The test groups were compared with control and standard by Tukey's multiple range test. The difference was considered statistically significant at $\mathrm{p}<0.05$.

\section{RESULTS}

Human anxiety is a feeling of unpredictability, trepidation, or emotional strain arising from the anticipation of fictitious or unreal threat. Anxiety has become an important research area in the field of central nervous system (CNS) disorders as it affects one-eighth of the population worldwide [19]. Benzodiazepines (BZDs), barbiturates, and antidepressants have been used for long time to treat anxiety disorders. The usage of these drugs in patients is limited due to the serious side effects, namely, rebound insomnia, drowsiness, withdrawal, sexual dysfunction, and impaired motor coordination [20]. In the present era, where mental disorders are highly prevalent and recognition of dreadful side effects and addiction liabilities associated with longterm administration of synthetic drugs have evoked the attention of researchers toward medicinal plants. Plants such as Withania somnifera, Valeriana officinalis, Nardostachys jatamansi, and Passiflora spp. have been used extensively in various traditional systems of therapy because of their adaptogenic and psychotropic properties. Inclusion of these well-established CNS affecting plants in modern therapeutics has reinvigorated the belief of researchers in natural products [21]. Despite the widespread traditional use of yellow sweet clover for treating various disorders, there are no reports of scientific evaluation of its anxiolytic activity; therefore, the present study was undertaken to explore the anxiolytic potential of the plant. The animal model used for evaluation of anxiolytic effect should have high ecological validity, should be based on the study of spontaneous behavior patterns and EPM test is the ideal model for studying the effect. The expression of anxiety by mice is exhibited by decrease in motor activity on EPM which is measured by time spent and number of entries in open arms [22].

The ethanol extract prepared from aerial parts of plant at dose levels of 100 and $200 \mathrm{mg} / \mathrm{kg}$ showed significant increase in time spent in open arms and mean number of entries in EPM (Fig. 1) and other extracts were found to be ineffective. The different extracts of roots of plants did not produce meaningful effect on EPM at the various test doses (Fig. 2).

An approach-avoidance conflict is exhibited by many animal species on placement of a mirror in their environment. The extended latency to enter the chamber of mirrors is used as a parameter of anxiety analogy [23]. In the mirror chamber test, the M. officinalis ethanol extract (aerial parts) increased the total number of entries and time spent by the animals in the mirror chamber at the dose of $200 \mathrm{mg} / \mathrm{kg}$

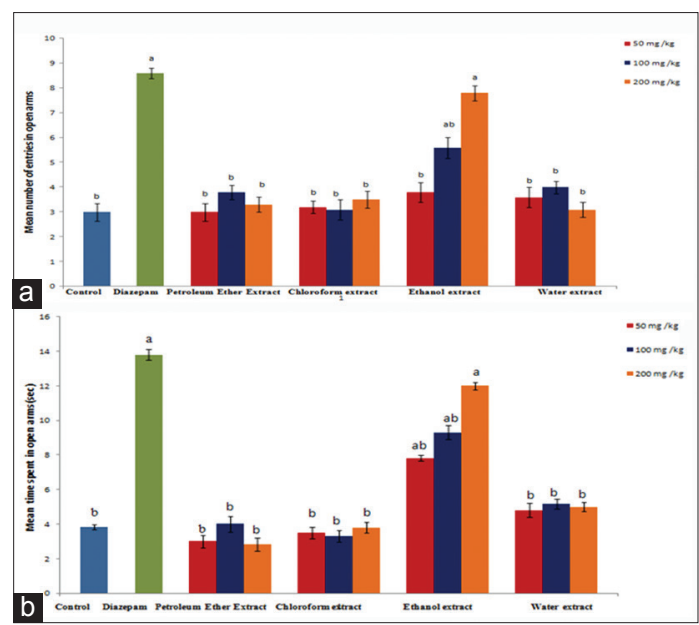

Fig. 1: Anxiolytic profile of $M$. officinalis (aerial parts) extracts. (a) Mean number of entries in open arms and (b) mean time spent in open arms. Values are expressed as mean \pm standard error mean $(n=6)$ a $p<0.05$ compared with vehicle-treated control, ${ }^{\mathrm{b}} \mathrm{p}<0.05$ compared with standard; one-way ANOVA followed by studentized Tukey's test 


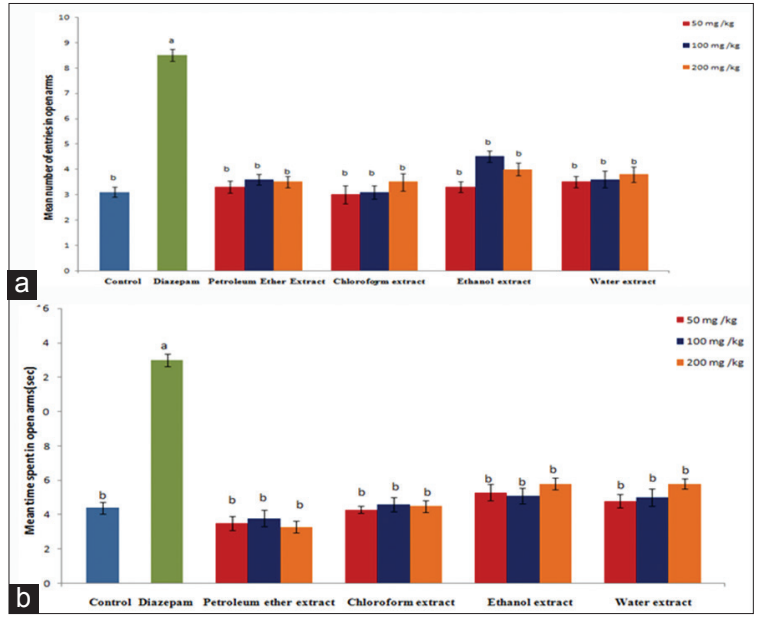

Fig. 2: Anxiolytic profile of M. officinalis (roots) extracts. (a) Mean number of entries in open arms and (b) mean time spent in open arms. Values are expressed as mean \pm standard error mean $(n=6)$ ${ }^{\mathrm{a}} \mathrm{p}<0.05$ compared with vehicle-treated control, ${ }^{\mathrm{b}} \mathrm{p}<0.05$ compared with standard; one-way ANOVA followed by studentized Tukey's test

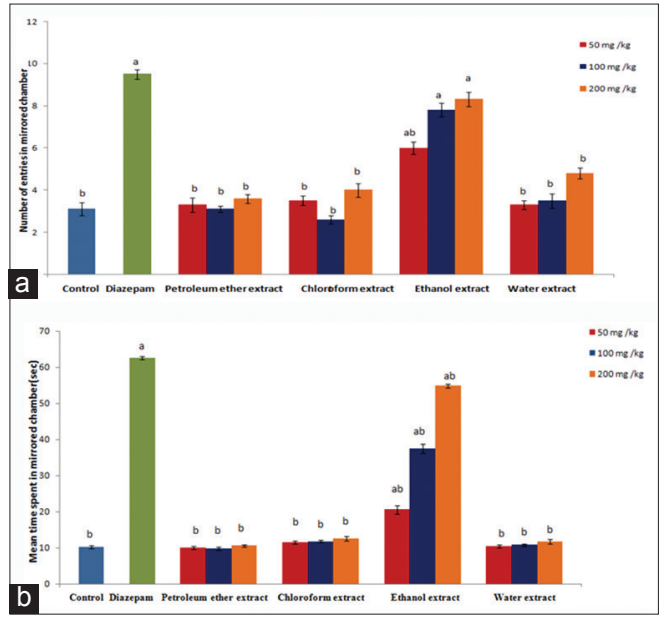

Fig. 3: Anxiolytic profile of M. officinalis (aerial parts) extracts in mirror-chamber model. (a) Mean number of entries in mirror chamber and (b) mean time spent in mirror chamber. Values are expressed as mean \pm standard error mean $(n=6)$. ${ }^{a} \mathbf{p}<0.05$ compared with vehicle-treated control, ${ }^{\mathrm{b}} \mathbf{p}<0.05$ compared with standard; one-way ANOVA followed by studentized Tukey's test

when compared with the control and standard group (Fig. 3). The root extracts were found to be devoid of anxiolytic activity as shown in Fig. 4. The roots extracts were unable to exhibit antianxiety activity in both the animal models, therefore, they were eliminated from further phytochemical investigation. The antianxiety response was partially reverted when doses were increased from $200 \mathrm{mg} / \mathrm{kg}$ due to sedative effects (data not shown), and therefore, no further evaluation was done.

\section{Phytochemical screening}

Various phytochemical tests performed on ethanol extract showed the presence of tannins, coumarin, flavonoids, amino acids, and carbohydrates.

\section{TLC-densitometry studies}

TLC-densitometry studies showed the presence of nine components in the bioactive ethanol extract as shown in Fig. 5 and Table 1.

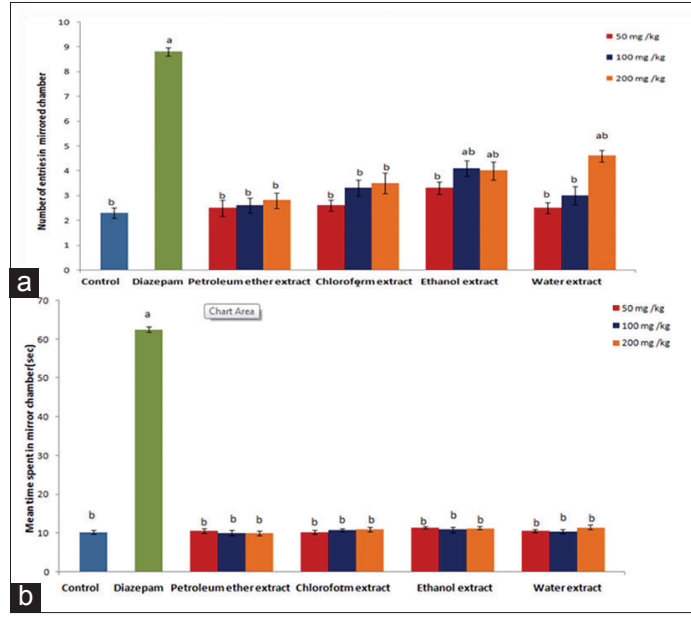

Fig. 4: Anxiolytic profile of $M$. officinalis (roots) extracts in mirror-chamber model. (a) Mean number of entries in mirror chamber and (b) mean time spent in mirror chamber. Values are expressed as mean \pm standard error mean $(n=6){ }^{a} p<0.05$ compared with vehicle-treated control, ${ }^{b} p<0.05$ compared with standard; one-way ANOVA followed by studentized Tukey's test

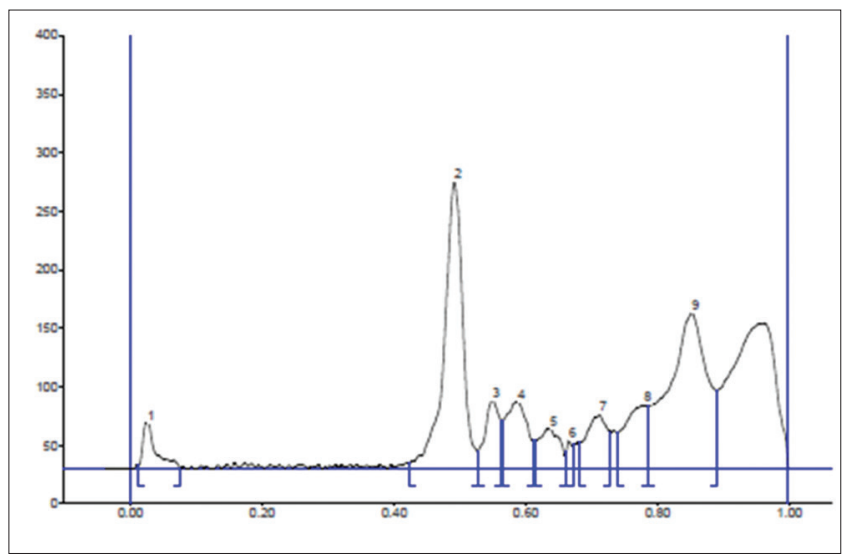

Fig. 5: TLC densitometric chromatogram of ethanol extract of M. officinalis

\section{DISCUSSION}

The results of the present study revealed that the ethanol extract possess anxiolytic effect at therapeutically acceptable doses. HPTLC studies on ethanol extract showed the presence of nine compounds. Preliminary phytochemical screening of ethanol extract exhibited the presence of flavonoids, coumarin, amino acids, carbohydrates, and tannins which implies that this plant is rich in phenolic components. Plants with high flavonoid content have been traditionally used as cure for nervous disorders and now they have been identified as a new type of ligand with in vivo anxiolytic properties [24]. A report has suggested that neuroprotective action of flavonoids is highly enhanced by the general bioavailability of flavonoids, and particularly by their presence (in vivo) in the brain [25]. Another study revealed that fractions from inflorescences of Tilia americana enriched in kampferol exerted anxiolytic activities in the EPM in mice [26]. A relatively mild or a high affinity for gamma-aminobutyric acid $\left(\mathrm{GABA}_{\mathrm{A}}\right)$ /BZD receptors with a partial agonist action have been shown by some flavonoids [27-29].

Another study reported that the coumarin derivatives are potent inhibitors of the enzyme monoamine oxidase [30]. It has been proposed that there is binding of coumarin derivatives with the BZD site of the $\mathrm{GABA}_{\mathrm{A}}$ receptor [31]. There are investigations indicating 
Table 1: The $R_{f}$ values of compounds present in ethanol extract

\begin{tabular}{|c|c|c|c|c|c|c|c|c|c|}
\hline Peak & Start $R_{\mathrm{f}}$ & Start height & $\operatorname{Max} R_{f}$ & Max height & $\operatorname{Max} \%$ & End $R_{f}$ & End height & Area & Area \% \\
\hline 1 & 0.01 & 2.8 & 0.02 & 39.8 & 5.72 & 0.08 & 1.1 & 723.6 & 3.45 \\
\hline 2 & 0.42 & 5.1 & 0.49 & 244.9 & 35.23 & 0.53 & 15.3 & 6196.2 & 29.57 \\
\hline 3 & 0.53 & 16.0 & 0.55 & 59.2 & 8.51 & 0.56 & 40.9 & 1149.7 & 5.49 \\
\hline 4 & 0.56 & 41.0 & 0.59 & 57.5 & 8.27 & 0.61 & 24.8 & 1711.9 & 8.17 \\
\hline 5 & 0.61 & 25.0 & 0.64 & 34.6 & 4.97 & 0.66 & 12.1 & 1006.6 & 4.80 \\
\hline 6 & 0.66 & 14.7 & 0.67 & 24.5 & 3.53 & 0.67 & 21.4 & 210.9 & 1.01 \\
\hline 7 & 0.68 & 22.8 & 0.71 & 46.5 & 6.69 & 0.73 & 32.0 & 1333.9 & 6.37 \\
\hline 9 & 0.79 & 53.6 & 0.85 & 133.5 & 19.20 & 0.89 & 67.2 & 6978.4 & 33.30 \\
\hline
\end{tabular}

that these modulation of monoamine oxidase (MAO) inhibitors modulate monoamine levels in the brain (dopamine, serotonin, and norepinephrine) and provoke behavioral modifications in rodents, thus exerting an anxiolytic effect. All these findings advocate that the mechanism underlying the anxiolytic activity of the plant may occur through the inhibition of MAO-A, increase in the GABAergic action, and increase in serotonin level, respectively, and phenolic compounds act as a ligand for receptors exerting anxiolytic and slight sedative effects. The anxiolytic effect of ethanol extract of aerial parts of plant could be due to the interaction of the phytoconstituents present in plant with these neural substrates. Therefore, the antianxiety action of $M$. officinalis could be related at least in part to compounds present in ethanol extract.

\section{CONCLUSION}

The present study validates the traditional claim of $M$. officinalis as cure for anxiety as ethanol extract of aerial parts produced a significant antianxiety effect. Since there is a need for new safer and cost-effective anxiolytic compounds with little side effects in contrast to synthetic medication, aerial parts of $M$. officinalis could be used to develop a safer anxiolytic drug. Further, phytochemical investigations are underway to isolate the active principles of plant responsible for the reported activity.

\section{ACKNOWLEDGMENT}

The authors duly acknowledge the financial assistance provided by the Department of Pharmaceutical Sciences, Guru Nanak Dev University, Amritsar, Punjab, India for this research work.

\section{REFERENCES}

1. Anwar MS, Mohtasheem M, Azhar I, Ahmed SW, Bano H. Chemical constituents from Melilotus officinalis. J Basic Appl Sci 2008;4(2):89-94

2. Plesca-Manea L, Pârvu AE, Pârvu M, Taamas M, Buia R, Puia M. Effects of Melilotus officinalis on acute inflammation. Phytother Res 2002;16:316-9.

3. Anwer MS, Shamim S, Ahmed S, Mohtasheemul M, Azhar I. Hypotensive activity of Melilotus officinalis (L.) Pallas. Eur J Med 2015;3(2):80-5.

4. Braga PC, Sasso MD, Lattuada N, Marabinil L, Calo R, Antonacci R, et al. Antioxidant activity of Melilotus officinalis extract investigated by means of the radical scavenging activity, the chemiluminescence of human neutrophil bursts and lipoperoxidation assay. J Med Plant Res 2013;7(7):358-65

5. Nasser NM, Al-Araji M, Widad MK. Antifungal activity of Mellilotus officinalis of Iraq. J Chem Pharm Res 2014;6(11):611-7.

6. Heidari MR, Najafi F, Asadi PA, Ansari M, Zahedi MJ, Vahedian M. Analgesic and ulcerogenic effect of methanolic extract of Melilotus officinalis. J Kerman Univ Med Sci 2001;8(4):210-68.

7. Martino E, Ramaiola I, Urbano M, Bracco F, Collina S. Microwaveassisted extraction of coumarin and related compounds from Melilotus officinalis (L.) Pallas as an alternative to soxhlet and ultrasound-assisted extraction. J Chromatogr 2006;1125:147-51.

8. Kang SS, Lim CH, Lee SY. Soyasapogenols B and E from Melilotus officinalis. Arch Pharm Res 1987;10(1):9.

9. Kang SS, Won SW. Melilotogenin, a new Sapogenin from Meliltous officnalis. J Nat Prod 1998;51(2):335-8

10. Manabu U, Junei K, Naotoshi Y, Toshihiro N. A new oleanene glucuronide having a branched chain sugar from Melilotus officinalis. Chem Pharm Bull 1998;46(3):526-7.

11. Sutiashvili MG, Alaniya MD. Flavonoids of Melilotus officinalis. Chem Nat Compd 1999;35(5):584.

12. Duke JA, Godwin MJ, Judi DC, Duke PK. Handbook of Medicinal Herbs. $2^{\text {nd }}$ ed. New York: CRC Press; 2002. p. 806-7.

13. Kumar M. Ethnobotanical studies on some medicinal plants: A review. World J Pham Res 2014;3(8):342-61.

14. Evans W. Trease and Evans Pharmacognosy. London: WB Saunders Company Ltd.; 1996. p. 98.

15. Kulkarni SK. Handbook of Experimental Pharmacology. $3^{\text {rd }}$ ed. Pitampura, New Delhi: Vallabh Prakashan; 2003. p. 135-40.

16. Malik R, Gilhaotra, NA. Novel non-receptor and non-gabaergic antianxiety-like activity of forskolin: Synergy with diazepam. Int J Pharm Pharm Sci 2015;7(2):200-3

17. Lamberty Y. The mirror chamber test for testing anxiolytics: Is there a mirror-induced stimulation? Physiol Behav 1998;64(5):703-5.

18. Khandelwal KR. Techniques and Experiments in Practical Pharmacognosy. Pune: Nirali Prakashan; 2003. p. 149.

19. Khanum F, Razack S. Anxiety-herbal treatment: A review. Res Rev Biomed Biotechnol 2010;1:71S.

20. Ravindran A, Manohar VR, Rai M, Raveendran N, Naik H. Chronic anxiolytic-like activity of aqueous extract of Coriandrum sativum seeds using elevated plus maze test in swiss albino mice. Int J Pharm Pharm Sci 2014;6(2):93-5.

21. Bloom FE, Kupfer DJ. Psychopharmacology: The Fourth Generation of Progress. New York: Raven Press; 1994. p. 1301.

22. Bhatacharya SK, Satyan KS. Experimental methods for evaluation of psychotropic agents in rodents: Anti-anxiety agents. Indian J Exp Biol 1997;35(6):565-75.

23. Kulkarni SK, Reddy DS. Animal behavioural models for testing antianxiety activity. Methods Find Exp Clin Pharmacol 1996;18:219-30.

24. Siqueira IR, Lara DR, Silva D, Gaieski FS, Nunes DS, Elisabersky E. Psychopharmacological properties of Ptychopetalum olacoides Bentham. Pharm Biol 1998;36(5):327-34

25. Dajas F, Rivera-Megret F, Blasina F, Arredondo F, Abin-Carriquiry JA, Costa G. Neuroprotection by flavonoids. Braz J Med Biol Res 2003;136(12):1613-20

26. Perez-Ortega G, Guevara FP, Chavez M, Herrera J, Martinez A, Martinez AL, et al. Sedative and anxiolytic efficacy of Tilia americana var. Mexicana inflorescences used traditionally by communities of State of Michoacan. M J Ethnopharmacol 2008;116(3):461-19.

27. Medina JH, Viola H, Wolfman C, Marder M, Wasowski C, Calvo D, et al. Overview - Flavonoids: A new family of benzodiazepine receptor ligands. Neurochem Res 1997;22(4):419-25.

28. Marder M, Estiu G, Blanch LB, Viola H, Wasowsk C, Medina JH, et al. Molecular modeling and QSAR analysis of the interaction of flavone derivatives with the benzodiazepine binding site of the GABA(A) receptor complex. Bioorg Med Chem 2001;9(2):323-35

29. Marder M, Paladini AC. GABA(A)-receptor ligands of flavonoid structure. Curr Top Med Chem 2002;2(8):853-67.

30. Seon HJ, Xiang HH, Seong SH, Ji SH, Ji HH, Lee D, et al. Monoamine oxidase inhibitory coumarins from the aerial parts of Dictamnus albus. Arch Pharm Res 2006;29:1119-24

31. Singhuber J, Baburin I, Ecker GF, Kopp B, Hering S. Insights into structure-activity relationship of GABAA receptor modulating coumarins and furanocoumarins. Eur J Pharmacol 2011;668(1):57-64 